\title{
PENENTUAN HARGA POKOK PRODUKSI PADA KOMODITAS CENGKEH DI KABUPATEN TOLITOLI
}

\author{
Fitriana1), Abd. Fattah'), Nurmala') \& Adnan Putra Pratama' ${ }^{2)}$ \\ 1) 2) Program Studi Agribisnis, Sekolah Tinggi IImu Pertanian (STIP) Mujahidin Tolitoli \\ Jl. Dr. Samratulangi, No. 51 Telp (0453) 22574, Tolitoli \\ email:fattahabd55@gmail.com
}

\begin{abstract}
Abstrak
Tanaman cengkeh merupakan salah satu komoditas unggulan di Kabupaten Tolitoli. Semakin tingginya biaya produksi dan dampak fluktuasi harga komoditas cengkeh menjadi masalah utama bagi para petani dalam membudidayakan komoditas ini. Penelitian ini bertujuan untuk mengetahui besarnya harga pokok produksi komoditas cengkeh di Desa Bilo Kecamatan Ogodeide Kabupaten Tolitoli (Studi Kasus Pada Kelompok Tani Cahaya Tani). Waktu penelitian dilaksanakan pada bulan Juli sampai bulan Agustus 2020. Metode penelitian yang digunakan adalah deskriptif analitis dengan sumber data berasal dari data primer yang dilakukan dengan cara wawancara menggunakan kuesioner dan data sekunder yang diperoleh dari Badan Pusat Statistik. Penentuan biaya produksi dilakukan dengan cara memperhitungkan biaya langsung dan tidak langsung dari seluruh komponen biaya usahatani. Hasil penelitian menunjukkan bahwa harga pokok produksi Komoditas Cengkeh di Desa Bilo Kecamatan Ogodeide Kabupaten Tolitoli (Studi Kasus Pada Kelompok Tani Cahaya Tani) yang diperoleh sebesar Rp. 22.042.024/Ha dengan Harga Pokok Produksi per kilonya sebesar Rp. 70.422.
\end{abstract}

Kata kunci: Biaya langsung dan biaya tidak langsung, harga pokok produksi, komoditas cengkeh

\begin{abstract}
Clove plant is one of the leading commodities in Tolitoli Regency. The higher production costs and the impact of fluctuating prices for clove commodities are the main problems for farmers in cultivating this commodity. This study aims to determine the cost of goods manufactured in Bilo Village, Ogodeide District, Tolitoli Regency (Case Study of the Cahaya Tani Farmer Group). When the research was conducted from July to August 2020. The research method used was descriptive analytical with data sources derived from primary data carried out by interviews using a questionnaire and secondary data obtained from the Central Statistics Agency. Determination of production costs is carried out with direct and indirect costs of all components of farm costs. The results showed that the cost of production of Clove Commodities in Bilo Village, Ogodeide District, Tolitoli Regency (Case Study at Cahaya Tani Farmer Group) was Rp. 22,042,024/ha with the cost of production per kilo of Rp. 70,422.
\end{abstract}

Keywords: Direct cost and indirect cost, cost of production, clove commodity

\section{PENDAHULUAN}

Cengkeh (Syzygium aromaticum) merupakan komoditas perkebunan yang banyak dibudidayakan oleh petani kecil di Indonesia. Peranan cengkeh terhadap perekonomian Indonesia cukup berdampak di mana Indonesia masih dikenal sebagai produsen utama cengkeh dunia sampai saat ini. Produk utama dari komoditas cengkeh yang banyak diekspor Indonesia ke luar negeri yaitu dalam bentuk bunga kering yang pada saat dipanen bentuknya berupa kuncup bunga.
Beberapa daerah sentra produksi cengkeh nasional berasal dari daerah Sulawesi, Maluku dan Pulau Jawa. Masalah ketidakpastian harga komoditas cengkeh seringkali membuat petani menelantarkan tanaman cengkehnya karena biaya pemeliharaan yang tinggi tidak sebanding dengan harga pembelian yang diterima petani (Suprihanti, 2020).

Cengkeh menjadi komoditas utama dalam pemenuhan kebutuhan bahan baku terutama bagi industri rokok kretek (Wahyudi, 2016). 
Dilain sisi dampaknya terhadap peningkatan pendapatan dan kesejahteraan petani, penyediaan kesempatan kerja di tingkat on farm dan off farm serta peningkatan devisa negara juga tidak kalah pentingnya untuk dijadikan perhatian oleh seluruh stake holder terkait. Hal ini disebabkan terjadinya dualisme ekonomi antara korporasi dan pertanian rakyat yang seringkali merugikan pihak petani cengkeh sebagai price taker yang didukung dengan kondisi pasar yang monopsoni (Pratama et al., 2020)

Pada tingkat nasional kondisi perkebunan cengkeh juga mengalami pasang surut yang disebabkan fluktuasi harga cengkeh yang cukup besar dan biaya panen dan pengolahan semakin tinggi. Karakteristik khas dari tanaman cengkeh yaitu dengan adanya panen besar diikuti panen kecil pada tahun berikutnya serta panen besar pada periode tertentu semakin memberi ketidak pastian dari sisi periode panen. Pada saat panen besar harga cenderung menurun yang mengakibatkan petani merugi dan kemudian tidak memelihara tanamannya. Hal tersebut mengakibatkan pertanaman kurang diperlihara dengan baik sehingga menyebabkan produksi menurun (Siregar, 2011).

Luas lahan usahatani cengkeh di Indonesia cenderung mengalami peningkatan setiap tahunnya khususnya pada periode tahun 2015 hingga 2019, akan tetapi produksi maupun produktivitas mengalami penurunan khususnya pada tahun 2017 dan mulai sedikit mengalami peningkatan pada tahun 2018 sampai dengan 2019 (Badan Pusat Statistik, 2020). Provinsi Sulawesi Tengah merupakan salah satu sentra produksi cengkeh yang pada tahun 2017 juga mengalami penurunan dalam jumlah produksi dan produktivitas. Produksi pada tahun 2017 hanya mencapai angka $5.314,10$ ton dengan luas lahan 71,454 ha sedangkan pada tahun 2016 produksi cengkeh mencapai $17.171,36$ ton dengan luas lahan 68,162 ha, namun kembali meningkat pada tahun 2018-2019. Kabupaten Tolitoli mempunyai wilayah administratif seluruhnya berjumlah 10 wilayah kecamatan yang terletak pada ketinggian 0-2.500 meter di atas permukaan dengan luas pengembangan komoditas cengkeh 37.804 ha dan produksi 9.418 ton (BPS Kabupaten Tolitoli, 2020).

Harga pokok produksi adalah biaya untuk menghasilkan produk pada perusahaan manufaktur (Samsul, 2013). Harga pokok produksi menurut Hansen dan Mowen mewakili jumlah biaya barang yang diselesaikan pada periode tertentu yang terdiri atas tiga komponen biaya utama yaitu biaya bahan langsung, biaya tenaga kerja langsung, dan biaya overhead (Widyantari et al., 2018).

Permasalahan pada sektor perkebunan cengkeh nasional sangat dirasakan pula dampaknya oleh petani cengkeh di level daerah. Mulai dari biaya pemeliharaan yang semakin meningkat, tenaga kerja yang semakin sulit didapatkan dan siklus panen yang tidak menentu. Hal ini tentu sangat mempengaruhi fokus dan minat petani dalam berusahatani dan terdapat kemungkinan yang dapat mengancam keberlangsungan dari komoditas cengkeh itu sendiri. Penelitian ini bertujuan untuk mengetahui besarnya Harga Pokok Produksi Komoditas Cengkeh di Desa Bilo Kecamatan Ogodeide Kabupaten Tolitoli dan diharapkan dapat menjadi bahan informasi bagi para petani cengkeh yang ada di Desa Bilo Kecamatan Ogodeide Kabupaten Tolitoli, dan juga dapat menjadi referensi bagi pemerintah dalam merumuskan kebijakan terkait harga komoditas cengkeh yang sering mengalami fluktuasi.

\section{BAHAN DAN METODE}

Jenis penelitian yang dilakukan adalah penelitian deskriptif yaitu penelitian yang memberikan gambaran atau fakta-fakta yang ada di lapangan atau menginterpretasi objek sesuai dengan apa adanya (Ndiba et al., 2016). Penelitian deskriptif biasanya dilakukan melalui survey, observasi, pengamatan langsung juga melalui wawancara. Setelah data terkumpul, kemudian ditabulasikan, diedit, dianalisis, dan diuraikan atau dijabarkan secara deskriptif. 
Penelitian ini dilakukan pada bulan Juli dan Agustus 2020. Lokasi penelitian terletak di Desa Bilo, Kecamatan Ogodeide, Kabupaten Tolitoli dengan pertimbangan Desa Bilo adalah salah satu sentra penghasil cengkeh di Kabupaten Tolitoli. Metode penentuan responden yang digunakan adalah secara purposive sampling dengan menentukan Kelompok Tani Cahaya Tani sebagai sampel penelitian sehingga responden dalam penelitian ini adalah seluruh anggota Kelompok Tani Cahaya Tani yang mengusahakan tanaman cengkeh yang berjumlah 25 orang yang berada di Desa Bilo, Kecamatan Ogodeide, Kabupaten Tolitoli. Selanjutnya dilakukan observasi dan wawancara mendalam kepada responden terkait data usahatani cengkeh dengan menggunakan kuesioner.

Metode analisis yang digunakan adalah perhitungan harga pokok produksi menurut Mulyadi dalam (Oentoe, 2013), dengan memperhitungkan unsur-unsur biaya kedalam produksi menggunakan dua pendekatan, yaitu metode full costing dan metode variable costing. Teknik analisis data yang digunakan dalam penelitian ini adalah metode full costing sebagai berikut :

\section{Biaya Langsung}

- Tenaga Kerja Langsung xx

Biaya Tidak Langsung

- Biaya Overhead Usahatani Tetap xx

- Biaya Overhead Usahatani Variabel xx

Total Biaya Produksi

Jumlah Produksi Sekali Panen $\quad$ xx

Harga Pokok Produksi/Kg

\section{HASIL DAN PEMBAHASAN}

\section{Produksi Usahatani Cengkeh}

Hasil penelitian menunjukkan bahwa produksi petani responden secara keseluruhan untuk usahatani cengkeh pada Kelompok Tani Cahaya Tani di Desa Bilo Kecamatan Ogodeide Kabupaten Tolitoli per periode produksi untuk luas lahan 24,48 ha adalah sebesar $7.670 \mathrm{Kg}$ dengan rata-rata sebesar $307 \mathrm{~kg}$ dari luas lahan rata-rata 0,92 atau 313 $\mathrm{kg} / \mathrm{ha}$ dengan luas lahan 1,00/ha. Potensi produktivitas tersebut masih bisa ditingkatkan hingga mencapai 1 ton/ha, akan tetapi minimnya peremajaan dan rehabilitasi tanaman serta kurangnya introduksi teknologi yang mutakhir dapat menjadi penghambat peningkatan dari produktivitas tanaman (Santoso, 2018)

\section{Biaya Langsung}

Biaya langsung yang digunakan dalam produksi usahatani cengkeh pada Kelompok Tani Cahaya Tani adalah biaya tenaga kerja. Hasil penelitian menunjukkan bahwa jumlah biaya rata-rata tenaga kerja langsung yang digunakan pada usahatani cengkeh Kelompok Tani Cahaya Tani di Desa Bilo Kecamatan Ogodeide Kabupaten Tolitoli sebesar Rp.16.568.883/ha dari luas lahan rata-rata/ha 1,00 ha, yang terdiri dari biaya land clearing sebesar Rp.725.082/ha dengan upah Rp.5.000/pohon, biaya pemupukan sebesar Rp.725.082/ha dengan upah Rp.5.000/pohon, biaya penyemprotan Rp.295.650/ha dengan upah Rp. 100.000, biaya penjemuran sebesar Rp.310.202/ha dengan upah Rp.50.000, biaya perontokan sebesar Rp.1.612.541 dengan upah Rp.500/liter dan yang menjadi komponen biaya tenaga kerja terbesar yaitu biaya pemetikan dengan biaya sebesar Rp.12.900.327/ha dengan upah Rp.4.000/liter. Biaya pemetikan menjadi komponen biaya terbesar karena jumlah tenaga kerja selama musim panen semakin langka ketersediaannya sehingga masyarakat mempekerjakan tenaga kerja dari luar daerahnya.

Kelangkaan tenaga kerja pada sektor pertanian saat ini menjadi masalah yang cukup serius untuk diperhatikan. Minimnya ketertarikan pada sektor pertanian khususnya generasi muda disebabkan oleh beberapa faktor antara lain pendapatan dari luar sektor pertanian yang lebih besar dibandingkan sektor pertanian atau dengan kata lain upah yang diterima pada sektor pertanian tergolong kecil, perspektif negatif terhadap sektor pertanian, kepemilikan lahan yang sempit dan akses yang sulit, serta peningkatan pendidikan (Nugroho et al., 2018). 


\section{Biaya Tidak Langsung}

Biaya overhead tetap merupakan biaya yang dikeluarkan dalam satu kali siklus produksi yang jumlahnya tidak berubah-ubah. Jumlah biaya rata-rata overhead tetap usahatani cengkeh pada Kelompok Tani Cahaya Tani di Desa Bilo Kecamatan Ogodeide Kabupaten Tolitoli sebesar Rp.483.967/ha yang terdiri dari biaya pajak lahan sebesar Rp.125.041/ha dengan luas lahan rata-rata/ha 1,00 ha. dan biaya penyusutan diperoleh berbagai macam alat yaitu wadah penampung, tangki sprayer, terpal, tali, cangkul, parang dan linggis. Jumlah biaya penyusutan alat yang dikeluaran oleh kelompok tani cahaya tani pada usahatani cengkeh adalah sebesar Rp.358.926/ha dengan luas lahan rata-rata/ha 1,00 ha.

Biaya overhead variabel merupakan biaya yang dikeluarkan usahatani cengkeh pada Kelompok Tani Cahaya Tani di Desa Bilo Kecamatan Ogodeide Kabupaten Tolitoli dalam satu siklus produksi dengan luas laha rata-rata/ha 1,00 ha sebesar Rp.4.989.175/ha, berikut rincian penggunaan biaya Overhead Variabel:

1) Berdasarkan anjuran teknis pemeliharaan Dinas Pertanian setempat untuk penggunaan pupuk berimbang untuk jenis pupuk phonska pada tanaman cengkeh dengan dosis pupuk awal musim hujan sebanyak 2.500 gr dan pada akhir musim hujan sebanyak $2.500 \mathrm{gr}$. Penggunaan pupuk yang digunakan kelompok tani cahaya tani yaitu pupuk phonska berjumlah $435 \mathrm{~kg} / /$ ha dengan pemberian dosis perpohonnya sebanyak $3 \mathrm{~kg}$ dengan biaya rata-rata/ha sebesar Rp.1.131.127. Penggunaan pupuk Za berjumlah $365 \mathrm{~kg} / \mathrm{ha}$ dengan pemberian dosis perpohonnya sebanyak $2,25 \mathrm{~kg}$ dengan biaya rata-rata/ha Rp.652.574/ha dan penggunaan pupuk Organik berjumlah $735 \mathrm{~kg} / \mathrm{ha}$ dengan pemberian dosis perpohonnya sebanyak $5 \mathrm{~kg}$ dengan biaya rata-rata/ha sebesar Rp.367.647.
2) penggunaan pestisida pada kelompok tani cahaya tani yaitu regent berjumlah 1,14 liter/ha dengan biaya rata-rata/ha sebesar Rp.137.255, Gramaxone berjumlah 3,51 liter/ha dengan biaya rata-rata/ha sebesar Rp.228.350 dan nakxone berjumlah 2,96 liter/ha dengan biaya rata-rata/ha sebesar Rp.236.928.

3) Penggunaan tangga pada kelompok tani cahaya tani dengan biaya rata-rata/ha sebesar Rp.2.205.882. Jenis tangga yang digunakan pada usahatani cengkeh yaitu tangga yang terbuat dari bambu.

4) Kemasan (karung) yang digunakan merupakan jenis karung beras dengan biaya rata-rata/ha sebesar Rp.29.412.

Penggunaan input yang efisien pada usahatani dapat meminimumkan biaya pemeliharaan sehingga tidak terjadi over budget. Hal ini menjadi penting karena seringkali petani belum mampu membedakan kandungan zat yang terdapat di dalam input khususnya pada pupuk sehingga pemberian pupuk seringkali melebihi dosis anjuran yang telah ditetapkan (Nurmala et al., 2015).

\section{Total Biaya}

Total biaya adalah jumlah keseluruhan biaya langsung yang terdiri dari biaya tenaga kerja, dan biaya tidak langsung yang terdiri dari biaya overhead tetap dan biaya overhead variabel yang dikeluarkan oleh petani untuk menghasilkan sejumlah produk dalam suatu periode tertentu. Hasil penelitian menunjukkan jumlah keseluruhan biaya Tenaga Kerja Langsung sebesar Rp.16.568.883/ha, Biaya overhead tetap sebesar Rp.483.967/ha di tambahkan dengan jumlah keseluruhan biaya overhead variabel sebesar Rp.4.733.736/ha dari luas lahan rata-rata 1,00 ha sehingga total biaya sebesar Rp.22.042.025/ha.

\section{Perhitungan Harga Pokok Produksi Usahatani Cengkeh}

Perhitungan harga pokok produksi usahatani cengkeh pada Kelompok Tani Cahaya Tani di Desa Bilo Kecamatan 
Ogodeide Kabupaten Tolitoli memperhitungkan semua unsur-unsur biaya dalam proses produksi. Hasil penelitian menunjukkan bahwa perhitungan harga pokok produksi usahatani cengkeh pada Kelompok Tani Cahaya Tani di Desa Bilo Kecamatan Ogodeide Kabupaten Tolitoli sebesar Rp.70.422 per Kilo dengan total biaya selama satu siklus produksi sebesar Rp.22.042.024. Menurut Crisdandi (2015), selain dipengaruhi oleh harga jual cengkeh di pasaran, besarnya biaya pemeliharaan yang dikeluarkan petani juga sangat memengaruhi terhadap besarnya pendapatan yang diterima oleh petani cengkeh ditambah dengan semakin menurunnya kualitas tanah dan tanaman yang membuat biaya pemeliharaan semakin membengkak

Untuk memperoleh harga pokok produksi yang lebih akurat, penggunaan metode full costing adalah hal yang tepat sehingga dapat diketahui pada harga berapa komoditas cengkeh yang ketika dijual dapat memberikan keuntungan yang layak bagi petani. Di sisi lain kesalahan dalam perhitungannya dapat menyebabkan kesalahan dalam pengambilan keputusan yang akan berdampak pada kerugian dalam ushatani (Maghfirah \& Syam BZ, 2016)

\section{SIMPULAN}

Berdasarkan hasil penelitian dapat disimpulkan bahwa perhitungan harga pokok produksi sangat penting untuk diketahui oleh semua stake holder yang terlibat dalam proses keberlanjutan usahatani cengkeh baik pihak petani, pemerintah maupun swasta atau perusahan sehingga dengan diketahuinya harga pokok produksi ini maka pemerintah dapat merumuskan regulasi terkait harga jual pemasaran cengkeh yang dapat memberikan harga yang cukup bagi petani sehingga dapat hidup lebih sejahtera. Di sisi lain juga dengan diketahuinya harga pokok produksi cengkeh petani dapat menilai apakah usahatani cengkeh dapat menjadi pilihan utama dalam kegiatan usahataninya atau petani mempunyai pilihan lain dengan menanam tanaman lain yang bisa memberi pendapatan tambahan bagi petani.

\section{DAFTAR PUSTAKA}

Badan Pusat Statistik. (2020). Indonesia Dalam Angka 2019. Retrieved from https://www.bps.go.id/publication/[2020/0 4/29]

BPS Kabupaten Tolitoli. (2020). Kabupaten Tolitoli Dalam Angka 2019. Badan Pusat Statistik Kabupaten Tolitoli.

Crisdandi, P. (2015). Pengaruh Biaya Pemeliharaan dan Harga Jual Terhadap Pendapatan Petani Cengkeh Di Desa Tirta Sari Pada Tahun 2014. Jurnal Jurusan Pendidikan Ekonomi (JJPE), 5(1), 1-11.

Maghfirah, M., \& Syam BZ, F. (2016). Analisis Perhitungan Harga Pokok Produksi dengan Penerapan Metode Full Costing pada UMKM Kota Banda Aceh. Jurnal Ilmiah Mahasiswa Ekonomi Akuntansi, 1(2), 59-70.

Ndiba, T. A. ., Wullur, M., \& Tumade, P. (2016). Evaluasi Kinerja Rantai Pasok Komoditas Cengkeh (Studi Pada Desa Lalumpe Kabupaten Minahasa). Emba, 4(1), 153164.

Nugroho, A. D., Waluyati, L. R., \& Jamhari, J. (2018). Upaya Memikat Generasi Muda Bekerja Pada Sektor Pertanian di Daerah Istimewa Yogyakarta. JPPUMA: Jurnal IImu Pemerintahan Dan Sosial Politik Universitas Medan Area, 6(1), 76. https://doi.org/10.31289/jppuma.v6i1.125 2

Nurmala, Antara, M., \& Hadayani. (2015). Efficiency Analysis of Production Input Uses of Clove Farming in Dako Pemean Sub District of Tolitoli Regency. Agroland; Jurnal IImu-IImu Pertanian, 22(3), 226234.

Oentoe, C. (2013). Analisis Perhitungan Biaya Produksi Menggunakan Metode Variable Costing. Jurnal EMBA, 1(3), 599-605.

Pratama, A. P., Darwanto, D. H., \& Masyhuri, M. (2020). The Impact of Government Policies on The Competitiveness Of Clove Commodity In Tolitoli Regency: Multi Period PAM Approach. Agro Ekonomi, 31(1). https://doi.org/10.22146/ae.55747

Samsul, N. H. (2013). Penentuan Harga Jual Perusahaan Dengan Metode Full Costing Pada PT. Danliris Di Sukoharjo. Jurnal EMBA, 1(3), 366-373. 
Fitriana, et al. 2021

Santoso, A. B. (2018). Upaya Mempertahankan Eksistensi Cengkeh di Provinsi Maluku Melalui Rehabilitasi dan Peningkatan Produktivitas. Jurnal Penelitian Dan Pengembangan Pertanian, 37(1), 26-32. https://doi.org/10.21082/jp3.v37n1.2018. p26-32

Siregar, A. R. (2011). Analisis Disparitas Harga dan Potensi Persaingan Tidak Sehat pada Distribusi Cengkeh. Jurnal Agribisnis, 10(3), 32-37.

Suprihanti, A. (2020). Analysis of Clove Agroindustry in Indonesia As an Alternative Green Industry. 4(Figure 1), 57-65.

Wahyudi, A. (2016). Strategi Stabilisasi Kinerja Pasar Cengkeh Nasional. Balai Penelitian Tanaman Rempah Dan Obat, 15(1), 7386.

Widyantari, N. W. L., Suamba, I. K., \& Dewi, I. A. L. (2018). Penetapan Harga Pokok Produksi Kacang Koro Pedang pada UD Laksmi Devi. Jurnal Agribisnis Dan Agrowisata (Journal of Agribusiness and Agritourism), 7(1), 31. https://doi.org/10.24843/jaa.2018.v07.i01. p04 
Fitriana, et al. 2021

\section{LAMPIRAN}

Tabel 1. Rata-rata Biaya Tenaga Kerja Langsung Usahatani Cengkeh pada Kelompok Tani Cahaya Tani di Desa Bilo Kecamatan Ogodeide Kabupaten Tolitoli Tahun 2020

\begin{tabular}{clr}
\hline No & \multicolumn{1}{c}{ Jenis Biaya } & Rata-rata/Ha (Rp) \\
\hline 1 & Land Clearing & 725.082 \\
2 & Pemupukan & 725.082 \\
3 & Peyemprotan & 295.650 \\
4 & Penjemuran & 310.202 \\
5 & Perontokan & 1.612 .541 \\
6 & Pemetikan & 12.900 .327 \\
\hline & Jumlah & $\mathbf{1 6 . 5 6 8 . 8 8 3}$ \\
\hline
\end{tabular}

Sumber: Data Primer Setelah Diolah, 2020

Tabel 2 . Rata-rata biaya Overhead Tetap Usahatani Cengkeh pada Kelompok Tani Cahaya Tani di Desa Bilo Kecamatan Ogodeide Kabupaten Tolitoli Tahun 2020

\begin{tabular}{clr}
\hline No & \multicolumn{1}{c}{ Jenis Biaya } & Rata-rata/Ha (Rp) \\
\hline 1 & Pajak & 125.041 \\
2 & Penyusutan Alat & \\
& a. Wadah Penampung & 46.160 \\
& b. Tangki Sprayer & 90.210 \\
& c. Terpal & 117.715 \\
d. Tali & 46.194 \\
e. Cangkul & 25.293 \\
& f. Parang & 23.999 \\
g. Linggis & 9.355 \\
\hline \multicolumn{2}{r}{ Jumlah } & $\mathbf{4 8 3 . 9 6 7}$ \\
\hline
\end{tabular}

Sumber : Data Primer Setelah Diolah, 2020

Tabel 3. Rata-rata biaya Overhead Variabe/ Usahatani Cengkeh pada Kelompok Tani Cahaya Tani di Desa Bilo Kecamatan Ogodeide KabupatenTolitoli Tahun 2020

\begin{tabular}{|c|c|c|}
\hline No & Jenis Biaya & Rata-rata/Ha (Rp) \\
\hline 1 & Pupuk & 2.151 .348 \\
\hline 2 & Pestisida & 602.533 \\
\hline 3 & Tangga & 2.205 .882 \\
\hline 4 & Kemasan (Karung) & 29.412 \\
\hline & Jumlah & 4.989 .175 \\
\hline
\end{tabular}

Sumber : Data Primer Setelah Diolah Tahun 2020

Tabel 4. Total Biaya Usahatani Cengkeh pada Kelompok Tani Cahaya Tani di Desa Bilo Kecamatan Ogodeide Kabupaten Tolitoli Tahun 2020

\begin{tabular}{rlr}
\hline No & \multicolumn{1}{c}{ Jenis Biaya } & Rata-rata/Ha \\
\hline 1 & Tenaga Kerja Langsung & 16.568 .883 \\
2 & Overhead Tetap & 483.967 \\
3 & Overhead Variabel & 4.989 .175 \\
\hline \multicolumn{2}{c}{ Total Biaya } & $\mathbf{2 2 . 0 4 2 . 0 2 5}$ \\
\hline
\end{tabular}

Sumber : Data Primer Setelah Diolah Tahun 2020 
Agrisaintifika

Jurnal Ilmu-Ilmu Pertanian

Vol. 5, No. 1, 2021

Fitriana, et al. 2021

Tabel 5. Hasil Perhitungan Harga Pokok Produksi Usahatani Cengkeh pada Kelompok Tani Cahaya Tani di Desa Bilo Kecamatan Ogodeide Kabupaten Tolitoli Tahun 2020

\begin{tabular}{|c|c|c|}
\hline \multirow{4}{*}{$\frac{\text { No }}{1}$} & Jenis Biaya & Total Biaya (Rp) \\
\hline & Biaya Langsung & \\
\hline & Biaya Tenaga Kerja & 16.568 .883 \\
\hline & Sub Total & 16.568 .883 \\
\hline \multirow[t]{11}{*}{2} & Biaya tidak Langsung & \\
\hline & Biaya Overhead Usahatani Tetap & \\
\hline & Pajak & 125.041 \\
\hline & Penyusutan Alat & 358.926 \\
\hline & Sub Total & 483.967 \\
\hline & Biaya Overhead Usahatani Variabel & \\
\hline & Pupuk & 2.151.348 \\
\hline & Pestisida & 602.533 \\
\hline & Tangga & 2.205 .882 \\
\hline & Karung & 29.412 \\
\hline & Sub Total & 4.989 .175 \\
\hline 3 & Total Biaya & 22.042 .024 \\
\hline 4 & Jumlah Produksi sekali Panen & $313 \mathrm{Kg}$ \\
\hline 5 & Harga Pokok Produksi/Kg & 70.422 \\
\hline
\end{tabular}

Sumber : Data Primer Setelah Diolah, 2020 